\title{
INSTRUMENTOS TOPOGRÁFICOS DEL SIGLO XVIII
}

\author{
(TOPOGRAPHICAL EQUIPMENT IN THE EIGHTEENTH CENTURY)
}

Teresa Sánchez Lázaro, Profesora Ayte. de la Cátedra de Transporte E.T.S. de Ingenieros de Caminos, Madrid - España

\section{RESUMEN}

Para valorar un proyecto antiguo es preciso saber en qué condiciones técnicas se hizo. Cuáles eran, por ejemplo, los medios disponibles para el estudio de la topografia en que la obra se iba a asentar, operación previa al levantamiento de los planos. Vamos a analizar, en las páginas siguientes, el equipo y los métodos topográficos de un ingeniero del siglo XVIII.

\section{SUMMARY}

An accurate evaluation of an engineering desing of the past requires a knowledge of the technical conditions under which it was drawn. For example, what were the resources available for the study of the topography on which the construction was going to be placed? Such a study must preceed the drawing of the plans of any preliminary sketch. On the following pages we will analyze the topographical equipment of an engineer of the end of the XVIIIth century.
El 22 de mayo de 1778 Jorge de Sicre, ingeniero comisionado en el reino de Aragón para el levantamiento de los planos necesarios para el proyecto de obras en la carretera de Zaragoza a Lérida (hoy tramo de $\mathrm{N}-\mathrm{II}$ ), dirigió a su superior una carta solicitando diversos útiles topográficos para llevar a cabo la labor encomendada.

Solicitaba a continuación:

"Tres perchas de 10 pies cada una para medir exactamente una base,

una cadena de 10 varas de largo eslabonada de pie a pie, para medir las distancias de los perfiles que se corten,

una plancheta,

dos niveles de agua,

un azadón,

dos banderas de bayeta de dos varas de ancho, mitad negra y mitad blanca, para que se distingan desde lejos, de cualquier modo que se proyecten, sea contra la falda de un monte o en el horizonte, cuatro mozos ágiles que nos sigan durante la comisión, para que una vez instruidos en el modo de manejar las reglas de nivelar, llevar los instrumentos de una parte a otra, medir distancias con la cadena y comprehender las señales que establezcamos para entendernos en las que la voz no alcanza, nos ahorren el trabajo y detención que ocasionaría el tomarlos nuevos en cada pueblo".

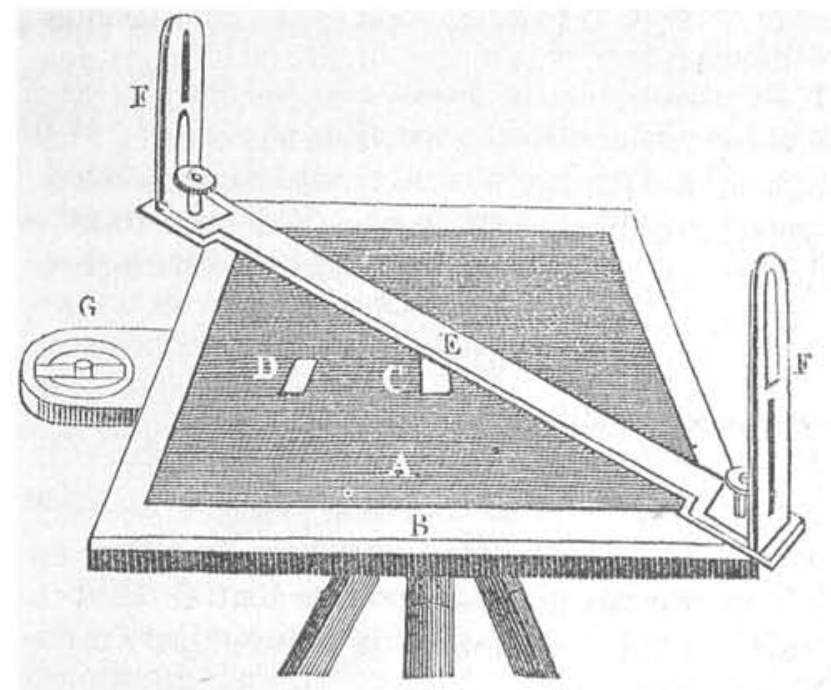

Fig. 1,-Esquema de plancheta, según Simms, A treatise on the prin. cipal mathematical instruments, London, 1865. 
Propone Sicre que, dado que hay que trabajar en descampado, alguno de los mozos sean elegidos de entre los miñones, para, de esta forma, poseer de paso escolta armada. Pide también unas tiendas de campaña para hacer noche inmediatos al trabajo y concluye presumiendo del equipo que él aporta:

"Yo traigo conmigo un cuadrante geográfico, un grafómetro o círculo entero, una plancheta inglesa, una brújula y dos reglas graduadas para nivelar, instrumentos que ni se hallarian, ni pudieran hacerse aquí, y de los cuales usaremos los oficiales que me acompañan y yo según lo pidan las circunstancias del terreno, para el más pronto y exacto desempeño de la comisión" [1].

Esta carta constituye un inventario, a nuestro entender bastante completo, de los útiles que formaban el equipo topográfico de un ingeniero de finales del siglo XVIII. El contraste entre la modestia de los medios y la importancia y perfección de los proyectos realizados es patente. Por lo que creemos que merece la pena reparar en cómo eran estos instrumentos y cuál su uso.

Para medir ángulos disponía Sicre de dos planchetas, un grafómetro, un cuadrante y una brújula.

La plancheta o mesilla, como la denomina Sánchez Taramas [2], era un tablero giratorio montado sobre un trípode mediante una rótula que permite situar el tablero en posición perfectamente horizontal. Sobre el tablero se fija el papel en el cual ha de trazarse el plano. Habia varios modos de hacerlo, Muller indica que "se pega con cola de boca" mientras que según Juan Justo Garcia "se afianza con un bastidor que coge el perimetro de la tabla" (Fig. 1). A continuación se mide sobre el terreno una base, en uno de cuyos extremos se sitúa la plancheta y en el otro una pica ("bandera de bayeta" en la carta de Sicre).

En el papel, en la posición y a la escala convenientes, se dibuja el segmento representativo de la base y desde el extremo correspondiente a la posición de la plancheta se dirigen visuales, mediante una alidada, a los distintos puntos o señales del terreno trazando sus direcciones sobre el papel. Después se intercambian la plancheta y la pica de los extremos de la base y se repite la operación desde la nueva posición de la plancheta. Se obtienen asi dos visuales correspondientes a cada punto del terreno cuya intersección en el papel será un punto representativo en el plano (Fig. 2) [3].

La plancheta ofrece la comodidad y rapidez del método gráfico y de aplicación directa, pero tiene también sus inconvenientes. En palabras de García: "El poco aparato que requiere el uso de este instrumento, le hace apreciable para determinar los puntos menos principales de un plan forjado ya por un método más exacto (...) Por lo demás suelen ser considerables los erro-

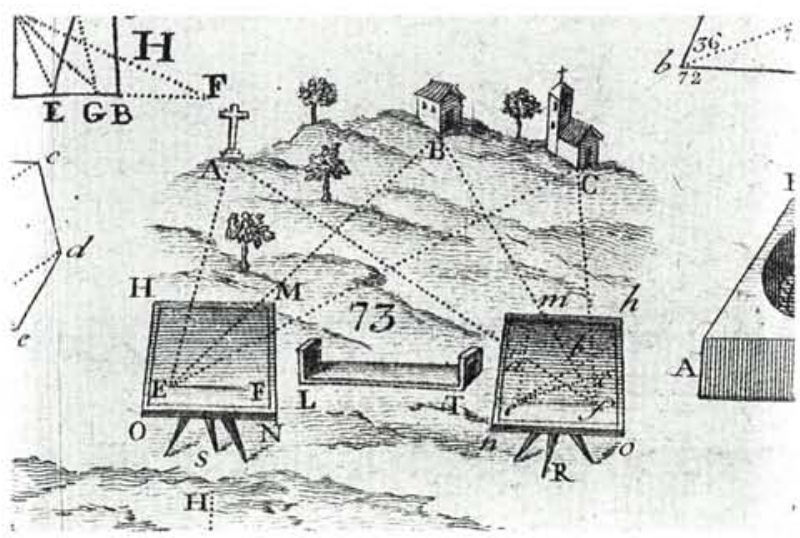

Fig. 2.-Uso de la plancheta, según García, Elementos de Aritmética (v. nota 4), Fig. 73.
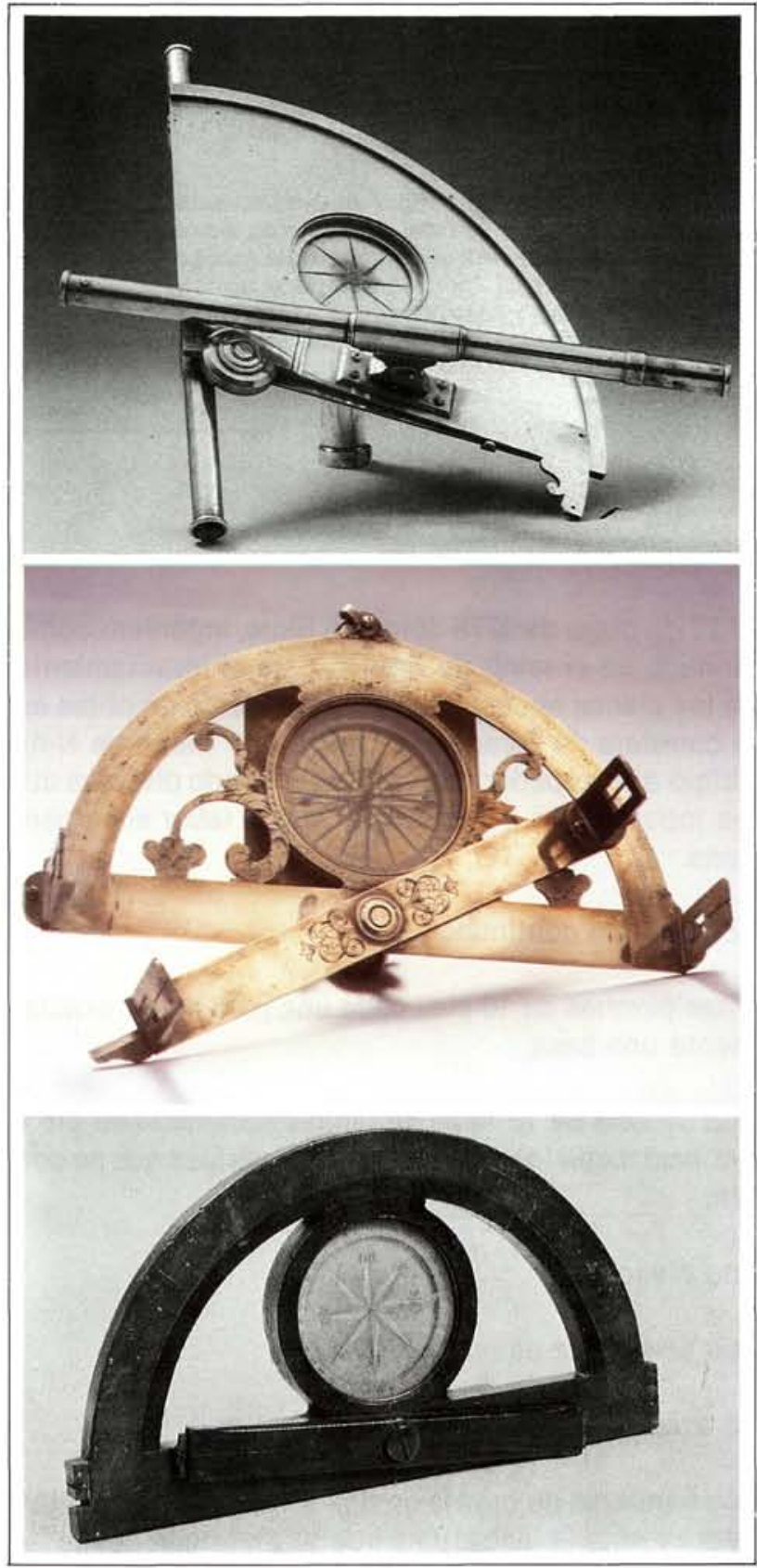

Fig. 3.-Cuadrante y grafómetros del siglo XVIII. Museo Arqueológico Nacional de Madrid (fotos cortesía del Museo).

http://informesdelaconstruccion.revistas.csic.es 


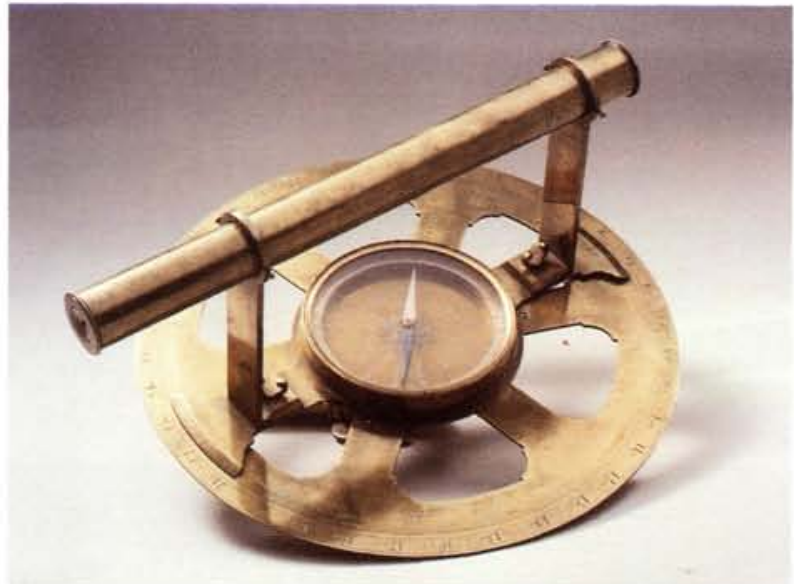

Fig. 4,-Grafómetro de finales del siglo XVIII. Museo Arqueológico Nacional. (Foto del Catálogo Instrumentos Cientificos de los siglos XVII y XVIII, Madrid 1987).

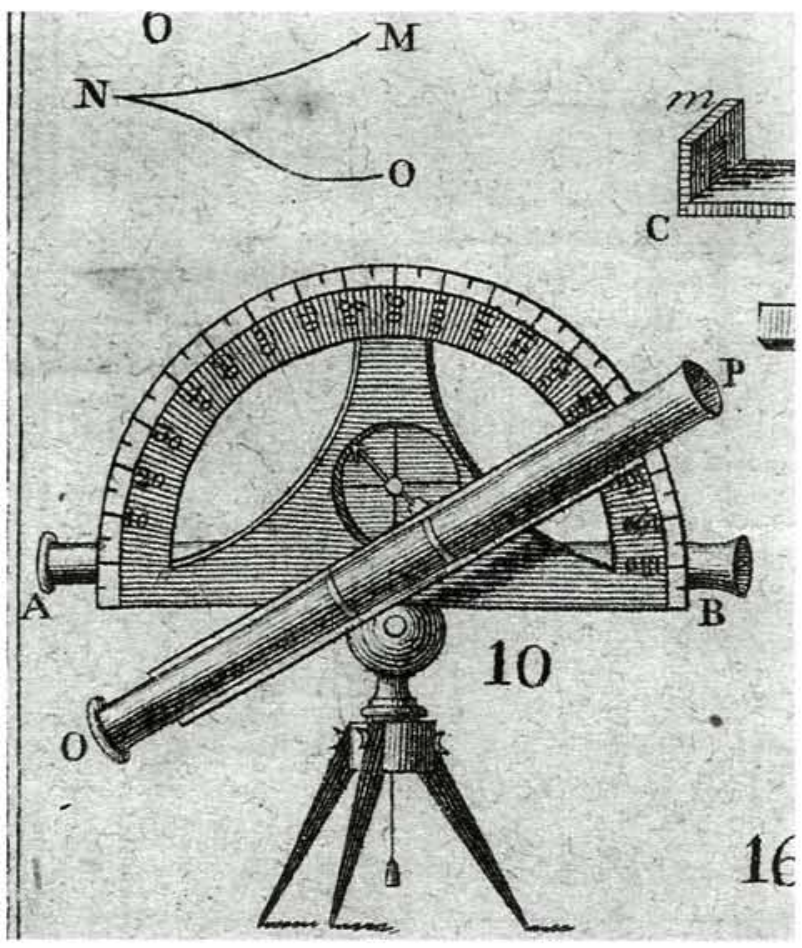

Fig. 5.-Grafómetro, según García (Fig. 10, Elementos de Aritmética...).

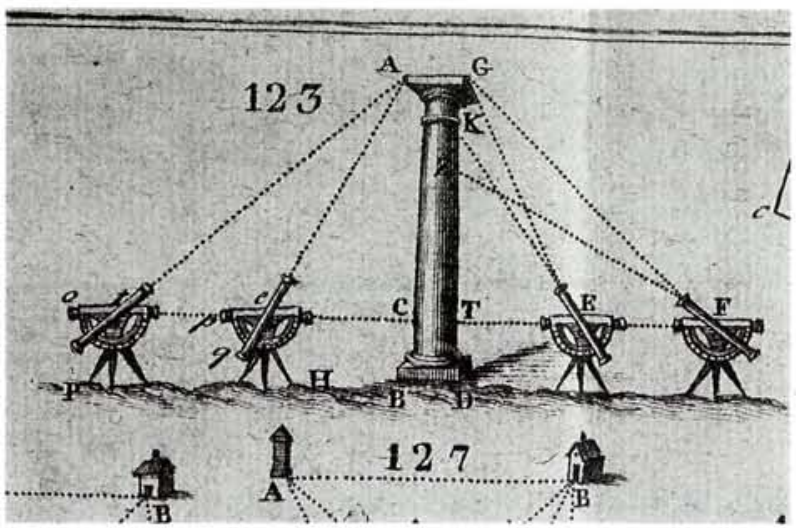

Fig. 6.-Uso del grafómetro, según García (Fig. 123, Elementos de Aritmética...). res que pueden resultar en el uso de la plancheta, ya por ser muy agudos los ángulos que sobre ella se forman, ya por estar el papel expuesto a moverse. Además de esto, cuando el mal temporal interrumpe la operación, hay que volverla a comenzar si se ha de hacer con exactitud" [4].

En el grafómetro, el tablero de la plancheta se sustituye por un arco de círculo, cuadrante, semicírculo (Fig. 3) o un círculo completo (Fig. 4) de diámetro entre 20 y $40 \mathrm{~cm}$, construido en latón y con el borde dividido en grados y fracciones, tan pequeños como permita la técnica del grabador. La división sexagesimal adoptada para los ángulos complicó notablemente la operación de realizar con exactitud esta división y es frecuente que los autores de la época, al tratar la cuestión, se pierdan en largas disquisiciones sobre el nada fácil problema de la trisección del ángulo.

El limbo "se coloca sobre un pie, y por medio de dos tornillos se le pone derecho, inclinado o en cualquier otra situación que requiera la dirección de las miras a los objetos que forman los ángulos. Para dirigir a éstos las líneas visuales hay una regla $o$ alidada movible alrededor del centro que tiene en medio una línea central con una flor de lis en su extremo, que señala los grados. Al lado de ella hay doce divisiones, cada una de las cuales equivale por lo común a 11/12 de grado o a 55', para sacar el valor del ángulo con más exactitud cuando la línea central no señala en el instrumento número fijo de grados" [5].

Hemos recogido la cita en toda su longitud porque es una de las escasas referencias al nonius o micróme. tro que hemos encontrado en la documentación de la época.

Acaba García su descripción con un sorprendente comentario que, si nos atenemos a otras referencias contemporáneas, debemos admitir que no es una errata. Dice García: "Cuando los objetos están a más distancia que de ocho a nueve mil varas $(7.500 \mathrm{~m})$, se usa de un anteojo que con otro colocado en el diámetro inmó. vil, descubre con más claridad los objetos". No cabe duda de que para Garcia la alidada de pínulas era más que suficiente (Figs. 5 y 6 ).

Este aparato permite la medición bastante exacta de ángulos cuyo valor ha de anotarse en lo que Garcia llama "libro de memorias", para después elaborar los datos mediante los cálculos trigonométricos necesarios hasta la obtención de los resultados que han de verterse en el plano.

Frente a la plancheta es éste, evidentemente, un procedimiento de mayor precisión pero que requiere más tiempo y preparación superior de la persona que realiza las mediciones. El uso de ambos instrumentos pue- 
de invertirse, aplicándolos a situar sobre el terreno detalles previamente dibujados en el plano [6].

En el Museo Arqueológico Nacional se conservan algunos grafómetros de esta época [7].

La brújula, de indiscutible utilidad como aparato auxiliar adosado a los anteriores, puede usarse también de forma independiente para el levantamiento de planos. Debe hacerse con mucha precaución pues, como García advierte: "Con ningún instrumento se levantan más fácilmente los planos que con la brújula; pero ninguno ocasiona mayores equivocaciones, ya sea por tomarse muy agudos los ángulos por la pequeñez de las agujas, ya sea por no haberse a caso apartado lo bastante de alguna mina de hierro; y en casa, de utensilios de hierro, puntas de compás o de otra brújula" [8] (Fig. 11).

Para la medición de distancias, Sicre necesitaba tres perchas de 10 pies cada una "para medir exactamente una base" y una cadena de 10 varas de largo eslabonada de pie a pie "para medir las distancias de los perfiles que se corten".

Las perchas eran reglones construidos de madera bien seca y de buena calidad para que se mantengan rectos, cuya longitud varía desde los 2,40 a 3 metros, como los que menciona Sicre, hasta los de 6 metros mencionados en el libro de Jorge Juan (Fig. 7). En ambos extremos iban provistas de cantoneras de cobre que delimitaban con precisión su longitud. Dada la poca estabilidad de la madera y la gran precisión exigida en su aplicación, las perchas debian de comprobarse, incluso varias veces al dia, por comparación con una longitud patrón. "La toesa de hierro que llevó Ms. Godin de París iba siempre con nosotros, la cual estaba marcada con gran prolijidad, y se ponía siempre a la sombra, donde ni el sol ni el agua la maltratasen y con el termómetro a su lado, para que nos diese el grado de calor o frío que tenía y se le pudiesen hacer las correcciones esenciales sobre este punto" [9].

Para establecer una base se tomarian una, dos o las tres perchas perfectamente alineadas y situadas horizontalmente poniendo una pica en cada extremo de la alineación así formada. Se trata de obtener dos puntos entre los cuales la distancia horizontal sea conocida con la máxima exactitud. Si la longitud de las tres perchas no es suficiente se pasará al tercer lugar la que ocupaba el primero, repitiendo la operación cuantas veces sea necesario.

La cadena se usaba con el mismo fin que hoy usamos las cintas métricas. A cada pie de longitud correspondia un eslabón característico para facilitar la lectura rápida, aunque no tan precisa como con las perchas. Los eslabones inicial y final tenían forma adecuada para ser utilizados como asideros en el tensado de la cadena (Fig. 8).
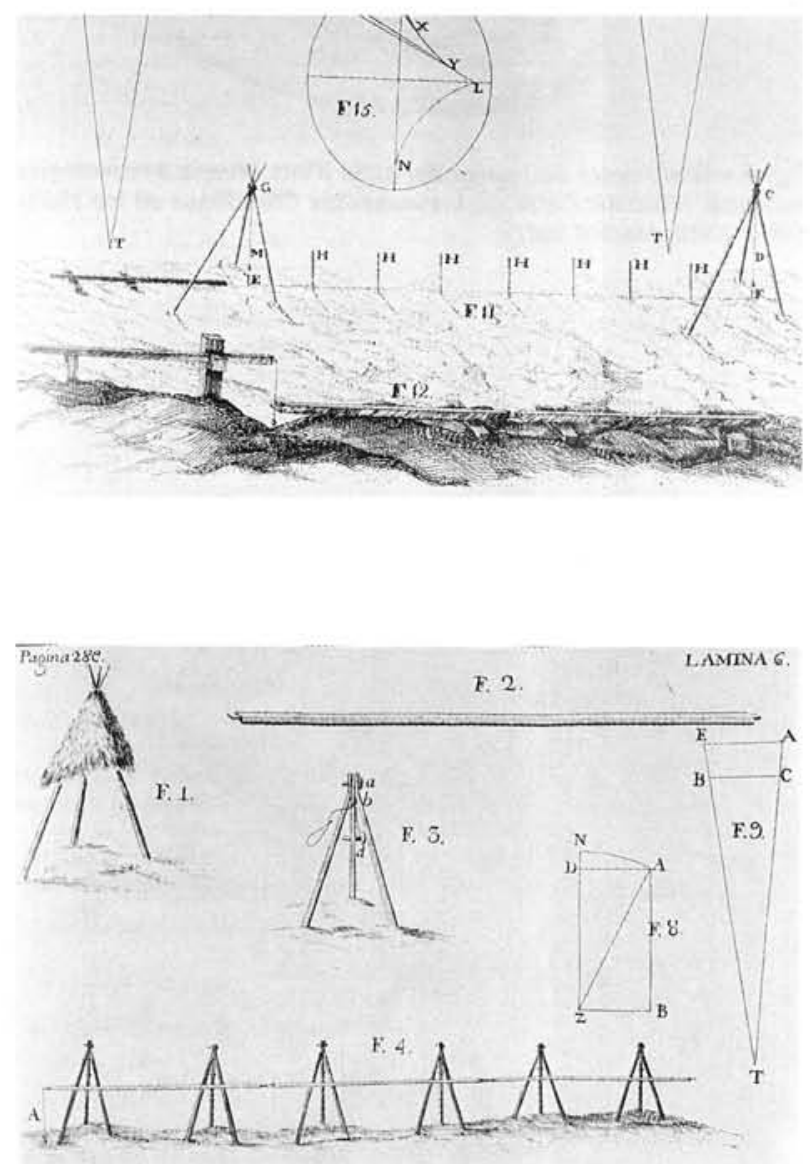

Fig. 7.-Perchas utilizadas por Jorge Juan y Ulloa para la medición del arco del meridiano, 1735-1746. (Lámina 6, Observaciones astronó. micas... Ver nota 9).

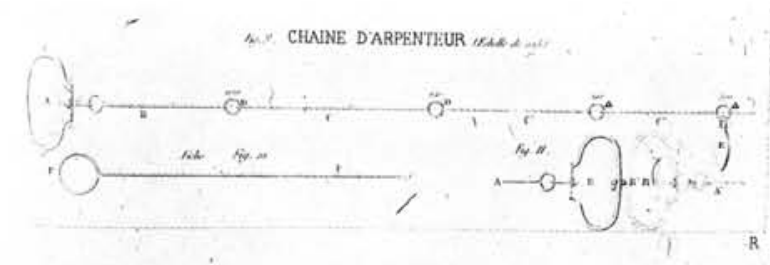

Fig. 8.-Cadena. Éste es un dibujo de 1858, pero la cadena es esencialmente igual a las del siglo XVIII.

http://informesdelaconstruccion.revistas.csic.es 


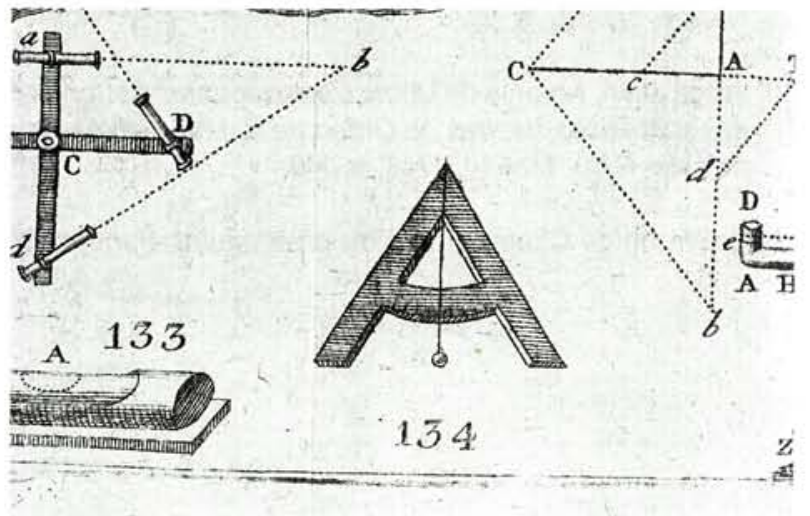

Fig. 9.-Nivel de perpendicula, según Garcia, Elementos de Aritmética..., Fig. 134.

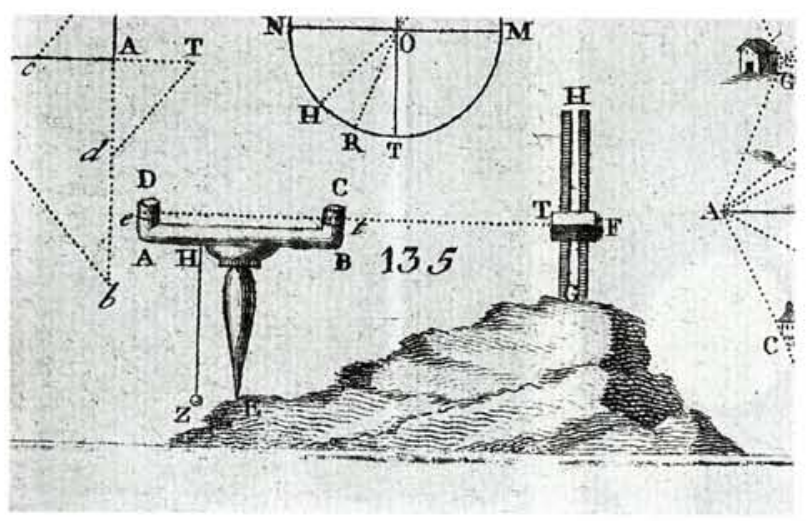

Fig. 10.-Nivel de agua, según Garcia, Elementos de Aritmética, Fig. 135.

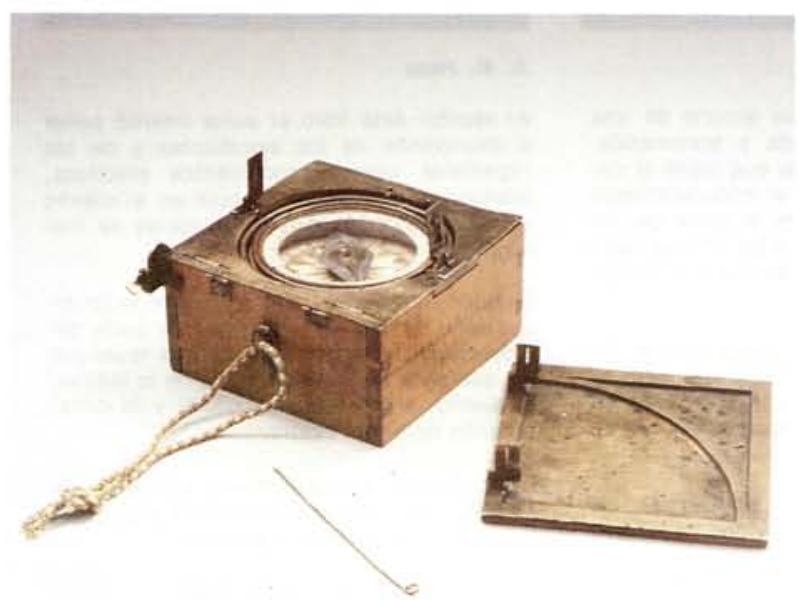

Fig. 11.-Brújula con pinulas. S. XVIII. Museo Arqueológico Nacional.

(C) Consejo Superior de Investigaciones Científicas Licencia Creative Commons 3.0 España (by-nc)
Es de importancia su aplicación para la medida de distancias entre los jalones de nivelación usados para determinar el trazado de los perfiles en el terreno, tal como indica Sicre en su carta.

Como instrumento de nivelación solicita Sicre dos niveles de agua. Es muy probable que por entonces el nivel de burbuja, que pronto habria de desplazar a todos los demás, no sea todavía perfecto ni usual.

A finales del XVIII se utilizan dos tipos de niveles, el de perpendícula - de albañil o de carpintero-y el nivel de agua. Los primeros se basan en la plomada, son bastidores de madera planos, de forma generalmente triangular o en cruz, dotados de una plomada (suspendida en lo alto del bastidor) que cuando pasa por un trazo vertical grabado en la parte inferior del bastidor indica que éste está apoyado en un plano perfectamente horizontal (Fig. 9). Puede ser acoplado a una regla de pínulas para dirigir visuales.

A pesar de que habia recibido notables perfeccionamientos que le permitian alcanzar cierta precisión, su uso resultaba mucho más engorroso y de menos precisión que el nivel de agua, quedando progresivamente limitado a los ámbitos artesanales que le dieron nombre.

El nivel de agua, basado en la horizontalidad de la superficie libre de los líquidos, está constituido por dos tubos cortos de vidrio que se sitúan verticalmente, unidos entre sí por un tercer tubo de 1 a 1,30 m de cobre o hierro esmaltado. Todo ello va montado de forma que pueda girar en torno a un eje vertical equidistante de ambos vidrios (Fig. 10). El instrumento había recibido muchos perfeccionamientos, encaminados la mayoría a resolver la imprecisión que comporta la forma de me. nisco de la superficie líquida, que la hace poco adecuada para ser utilizada como mira de alidada. Así, La Hire propuso adaptarle un sistema de pinulas flotantes, Mariotte un anteojo de Galileo flotante, etcétera [10].

Complemento indispensable del nivel son las reglas graduadas o miras sobre las cuales se dirigirá la horizontal obtenida con el nivel que la cortará en un punto cuya altura sobre el suelo será leída en la mira.

Otros útiles accesorios como las picas, las banderolas y los mojones tienen por objeto señalar, de forma relativamente permanente, los puntos de referencia utilizados en el levantamiento de planos y en la nivelación. Parece que estas señales disfrutaban de la animadversión de los honrados campesinos de nuestro país, hasta el punto de que Jorge de Sicre prevé en la carta la necesidad de "amonestar a los Alcaldes de los Lugares (...) para que no se quiten las señales que pongamos". 


\section{NOTAS}

[1] Archivo General de Simancas, S. ${ }^{a}$ S. ${ }^{a}$ H. ${ }^{a}$, leg. 921.

[2] Muller, Juan, Tratado de Fortificación o Arte de construir los Edificios Militares y Civiles, traducción y notas de Miguel Sánchez Taramas, Madrid, 1769, Tomo I, pp. 245-252.

[3] Parece ser que la plancheta fue un invento de Leonhard Zubler (1563-1609), orfebre y mecánico de Zürich que la puso a la venta como "un nuevo instrumento geométrico que permite medir todas las dimensiones de altura, anchura, longitud y profundidad fácilmente y sin cálcuIo". Alrededor de 1600 Johannes Praetorius, profesor de la Universidad de Altorf, la popularizó, razón por la cual se le llama a menudo "ménsula paetoriana" (Straub, A. H. of Civil Engineering, London, 1960).
[4] Garcia, Juan Justo, Elementos de Aritmética, Álgebra y Geometria, Salamanca, 1782, p. 63.

[5] Garcia, op. cit., pp. 11-12.

[6] Como hace Muller, op. cit., pp. 245-247.

[7] Tenemos noticia de que se conservan tres, que han sido reproducidos y comentados en el Catálogo Instrumen tos Científicos de los Siglos XVII y XVIII, Madrid, 1987.

[8] García, op. cit., p. 65

[9] Jorge Juan, Antonio de Ulloa, Observaciones Astronómicas y Phisicas hechas de Orden de S. Mag. en los Reynos del Péru, Madrid, 1748, p. 149.

[10] V. Breton de Champ, Traité du nivellement, Paris, 1861.

\section{publicaciones del ICCET/CSIC}

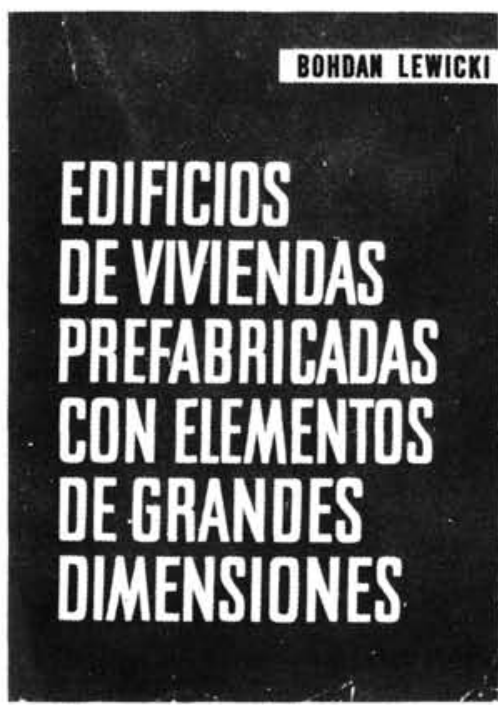

Bohdan Lewicki

Este libro trata de los problemas relativos a la construccion de los edificios de viviendas o publicos realizados con elementos prefabricados de grandes dimensiones. Se han estudiado los problemas de arriostramiento, asi como los que plantea la resistencia de los elementos y de la estructura; se han examinado las cuestiones de orden higrotérmico, acústico y de resistencia al fuego: tambien se ha profundizado en el estudio de la estanquidad de los muros exteriores y de las juntas.

La obra incluye numerosas ilustraciones que dan detalles de diversas soluciones, asi como ejemplos de cálculo, tabias de valores numéricos, diagramas y ábacos.

Un volumen encuadernado en tela, de $24 \times 17 \mathrm{~cm}$, compuesto de 616 págs.

Precios: 2.500 ptas.; \$USA 36.00

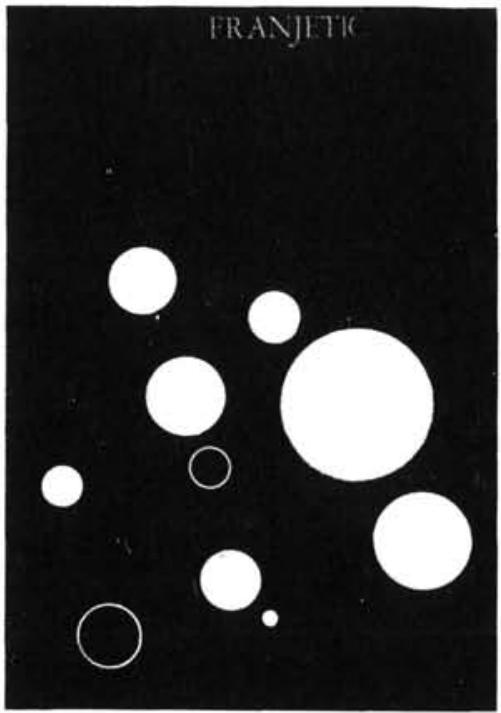

Zorislav Franjetić

En la obra de Franjetic se expone de una forma minuciosa, ordenada y sistemática todo un cuerpo de doctrina que reúne el co nocimiento actual sobre el endurecimiento rápido del hormigon. Parte el autor de los principios básicos y llega a las últimas consecuencias y realidades técnicas y economicas.

Es una obra de consulta, tanto para el investigador sobre la materia, como para el proyectista y el realizador y montador de plantas e instalaciones y equipos de curado y endurecimiento rápido.

Un volumen encuadernado en cartoné, de $17 \times 24,5 \mathrm{~cm}$, compuesto de 385 págs. 110 figuras y 10 tablas

Precios: 2.500 ptas.; \$USA 36.00

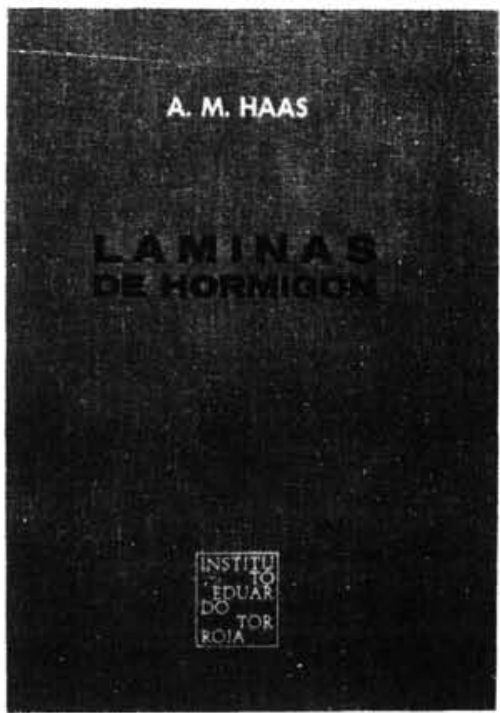

A. M. Haas

Al escribir este libro el autor intento poner a disposición de los estudiantes y de los ingenieros unos conocimientos prácticos, adecuados para servir de guia en el diseño y construcción de láminas delgadas de hormigón.

El autor está convencido de que el éxito en el diseño de una lámina exige, por parte de proyectista, un examen de las tres fases por las que pasa la materialización de la lámina: el diseño, el análisis estructural y la construcción de la estructura.

Un volumen encuadernado en tela, de $17 \times 24,5 \mathrm{~cm}$, compuesto de 420 oágs., 141 figuras, 22 fotografias y 6 tablas.

Precios: 2.500 ptas.; SUSA 36.00 